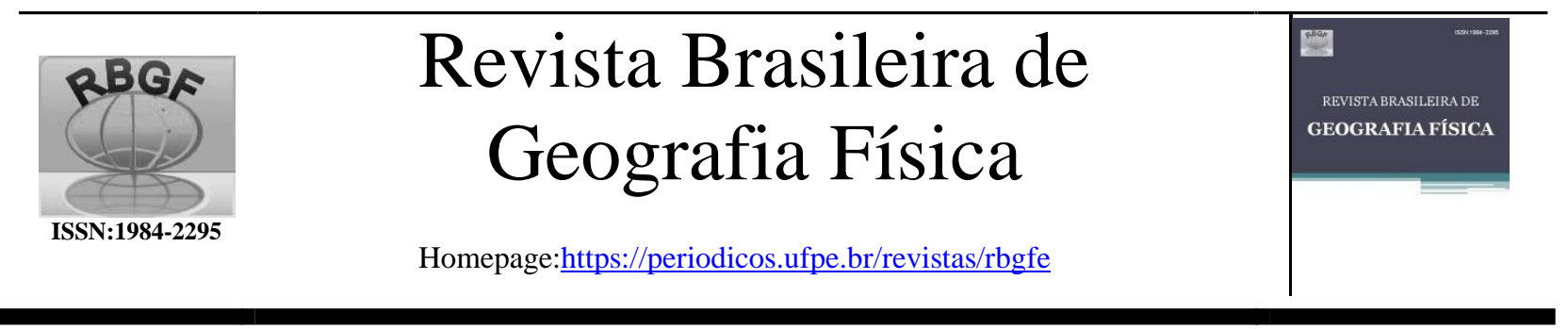

\title{
Índice de Vulnerabilidade Socioambiental na Área da Gleba “C” da Universidade Federal do Pará, no Município de Belém
}

\author{
Maria Carolina Chaves de Sousa ${ }^{1}$, Peter Mann de Toledo ${ }^{2}$, Filipe Gomes Dias ${ }^{3}$
}

\begin{abstract}
${ }^{1}$ Mestre em Ciências Ambientais pela Universidade Federal do Pará. Bacharel em Direito pela Universidade da Amazônia - Belém/Pará (PA) e Engenheira Ambiental pela Universidade Estadual do Pará - Belém/Pará (PA). Rua Augusto Corrêa, 01, CEP 66075-110, Belém, Pará, mary.carolina@gmail.com (autor correspondente). ${ }^{2} \mathrm{PhD}$ em Geologia pela Universidade do Colorado - Denver (CO), Estados Unidos. Professor pesquisador titular do Instituto Nacional de Pesquisas Espaciais e professor orientador do Programa de Pós-Graduação em Ciências Ambientais da UFPA. Avenida dos Astronautas, 1758, CEP 12227-010, Sao Jose dos Campos, São Paulo, peter.toledo@hotmail.com. ${ }^{3}$ Mestre em Ciências Ambientais pela Universidade Federal do Pará. Graduado em Geografia pela Universidade do Estado do Pará. Especialista em Gestão Ambiental e Manejo de Paisagem pelo Núcleo de Altos Estudos Amazônicos (NAEA) da Universidade Federal do Pará. Rua Augusto Corrêa, 01, CEP 66075-110, Belém, Pará,fgdiass02@gmail.com.
\end{abstract}

Artigo recebido em 21/08/2020 e aceito em 24/03/2020-19/04/2021

\section{R E S U M O}

No início do século XX, a urbanização e ocupação de espaços privilegiados em detrimento de espaços de "baixada" e próximos a várzea. As "baixadas" foram ocupadas por uma população, em sua maioria, com carências socioeconômicas, formando-se conjuntos de habitações suscetíveis à alagamentos e enchentes. Para trazer reconhecimento de direitos a esses ocupantes, foi realizado um trabalho de regularização fundiária pela Universidade Federal do Pará - UFPA, em conjunto com entes públicos do Estado e da União. O artigo objetiva apresentar e comparar o grau de vulnerabilidade socioambiental da área da gleba $\mathrm{C}$ da UFPA no município de Belém, objeto de atividade de regularização fundiária, aplicando indicadores e índices relacionados às questões sociais, econômicas, jurídicas e ambientais. Os resultados mostram que o grau de vulnerabilidade é alto nos anos pesquisados, concluindo que o trabalho de regularização jurídica realizada na área foi apenas patrimonial, a fim de transferir responsabilidades de uso da terra aos moradores beneficiários e de reconhecimento de direito desse título por força de lei. Um trabalho efetivo de regularização fundiária deveria envolver um conjunto de órgãos responsáveis pela área social, ambiental, urbanístico e fundiário para que, de forma concatenada e a longo prazo, realizar os trabalhos necessários para que os resultados sejam captados pelos indicadores e que efetivamente diminuam o grau de vulnerabilidade socioambiental na área estudada.

Palavras-chave: Vulnerabilidade Socioambiental; Indicadores; Universidade Federal do Pará.

\section{Index of Socio-Environmental Vulnerability in the Amazon: Study of Gleba "C" of the Federal University of Pará, in the Municipality of Belém}

\begin{abstract}
At the beginning of the 20th century, urbanization and occupation of privileged spaces at the expense of "lowland" spaces and close to a floodplain. The "lowlands" were occupied by a population, mostly with socioeconomic needs, forming housing groups susceptible to flooding and flooding. To bring the recognition of rights to these occupants, a land regularization work was carried out by the Federal University of Pará - UFPA, together with public entities from the State and the Union. The article aims to present and compare the degree of socio-environmental vulnerability in the area of land C of UFPA in the municipality of Belém, object of land regularization activity, applying indicators and indices related to social, economic, legal and environmental issues. The results show that the degree of vulnerability is high in the years surveyed, concluding that the legal regularization work carried out in the area was only patrimonial, in order to transfer responsibilities for land use to the beneficiary residents and the recognition of the right of that title by
\end{abstract}


law. . Effective land regularization work should involve a set of bodies responsible for the social, environmental, urban and land areas so that, in a concatenated and long-term manner, the work carried out is carried out so that the results are captured by the indicators and that the data decrease the degree of socio-environmental vulnerability in the studied area. Keywords: Socioenvironmental Vulnerability; Indicators; Federal University of Pará.

\section{Introdução}

$\mathrm{O}$ conceito de vulnerabilidade possui um caráter multidimensional, dessa forma as abordagens podem ser divididas em categorias como: vulnerabilidade física, vulnerabilidade econômica e vulnerabilidade social (Diaz-Sarachaga; Jato-Espino, 2020). Para Cartier et al. (2009), a vulnerabilidade socioambiental é entendida como a combinação de fatores socioeconômicos e ambientais caracterizada pela ocupação de áreas de risco e ambientalmente degradadas por grupos sociais discriminados e privados materialmente.

Cutter (1996) explica que o risco interage com a mitigação para produzir o perigo potencial, sendo que esse potencial é moderado ou reforçado por um filtro geográfico (local e sua situação), bem como o tecido social do lugar, que inclui a experiência da comunidade com riscos e a capacidade de responder lidar, recuperar e se adaptar a eles, que, por sua vez, são influenciados por fatores econômicos, demográficos e habitacionais. Assim, o aumento das ações mitigadoras poderá significar a diminuição do risco e, consequentemente, implicará a redução da vulnerabilidade do lugar. Por outro lado, o risco poderá aumentar se houver alterações no contexto geográfico ou na produção social, que poderão incorrer no aumento da vulnerabilidade ambiental e social (respectivamente) e da vulnerabilidade do lugar.

Situações adversas decorrentes do processo de urbanização - construções de moradias em locais inadequados, por exemplo - são um agente vulnerável e que pode vir a causar vulnerabilidade, riscos e danos ao meio e ao homem como parte da natureza.As estruturas ilegais de ocupação que se encontram estabelecidas na maioria das cidades brasileiras expõem o processo desigual de produção do espaço urbano. O processo de crescimento das cidades não é somente desigual, mas também possui um caminho próprio em cada lugar de construção no que tange às desigualdades, a exclusão das minorias (Cabral e Cândido, 2019).

Falar de vulnerabilidade em contexto de ordenamento territorial é relativamente recente, visto que tal conceito era mais utilizado para avaliação de riscos e desastres naturais, sendo na década de 1980 o surgimento de uma abordagem teóricometodológica que refletisse não somente aspectos físicos dos desastres, mas também aspectos sociais, econômicos, ambientais e culturais das populações atingidas (Almeida, 2012).

Marandola Jr. e Hogan (2006) apontam que os geógrafos foram os primeiros a trazerem a vulnerabilidade para o debate ambiental no contexto de estudos sobre riscos e também entendem a necessidade de análise interdisciplinar da vulnerabilidade, visto que os perigos ocorrem na relação/interface sociedade-natureza, e não incorporar (ou fazê-lo de forma relativa) o contexto social e geográfico pode limitar as análises a relações causais simples, pouco elucidativas das complexas tramas envolvidas.

Em Belém, especialmente no final do século XIX e início do século XX, a ocupação de espaços obedeceu a duas tendências: a oficial, especialmente com o Intendente Antônio Lemos, e a não oficial, com aumento o número de habitações coletivas (cortiços, casas de cômodo e hotéis) e o afastamento espacial de pessoas (migrantes, compostos principalmente por nordestinos e estrangeiros) das áreas centrais. Para essas pessoas, restou ocupar áreas de terra firme e de várzea, consideradas topograficamente mais baixas e propensas a alagamentos sazonais, com pouca ou nenhuma infraestrutura (Silva e Rocha, 2019).

Além desse contexto e processo em que são criados espaços urbanos vulnerabilizados, o problema se mostra ainda mais complexo quando se analisa situações onde ocorreram iniciativas de planejamento urbano para enfrentar as mazelas e propiciar um quadro socioambiental favorável, como a criação de espaços de instituições oficiais federais, em meados do século XX, em especial a Universidade Federal do Pará - UFPA. A Universidade foi o espaço de atuação da Comissão de Regularização Fundiária da UFPA (CRF/UFPA), visto o Decreto s/n, de 1991, autorizou a alienação de parte da área aos ocupantes até então irregulares (UFPA, 2010).

Pela condição de renda da população ocupante, não foi possível alienar os lotes à eles. A alternativa para possibilitar a regularização foi a Concessão de Uso Especial para Fins de Moradia (CUEM). Instrumento jurídico inaugurado na Constituição Federal de 1988 para garantir o direito da população de baixa renda que ocupava assentamentos consolidados em áreas públicas, 
consubstancia-se na regularização fundiária da posse e na promoção da urbanização do local sem recorrer, como de regra (Pereira, 2020).

Para que o morador tenha direito a receber a CUEM, atualmente, deve cumprir os requisitos legais de possuir como seu, até 22 de dezembro de 2016, por cinco anos, ininterruptamente e sem oposição, até duzentos e cinquenta metros quadrados de imóvel público situado em área com características e finalidade urbanas, e que o utilize para sua moradia ou de sua família, desde que não seja proprietário ou concessionário, a qualquer título, de outro imóvel urbano ou rural (Art. $1^{\circ}$, MP 2.220/2001). No texto exarado em 2001, a data de cumprimento temporal da posse era 30 de junho de 2001 (Brasil, 2001). Sendo beneficiado pela CUEM, o morador é apenas possuidor do bem, sendo o proprietário do bem imóvel a Administração Pública.

O objetivo precípuo deste artigo é comparar o grau de vulnerabilidade socioambiental antes (ano 2000) e após as titulações (ano 2010) de Concessão de Uso Especial para Fins de Moradia aos moradores da gleba $\mathrm{C}$ da UFPA. Para alcançar esse objetivo, este trabalho utilizará indicadores e índices para montar o Índice de Vulnerabilidade Socioambiental (IVSA).

A hipótese trabalhada é de que o trabalho de regularização realizado não

abrangeu todos os aspectos do qual a

legislação sobre o tema assume, fazendo, assim, com que o contrato administrativo realizado para beneficiar o morador, por si só, tenha influenciado apenas na segurança jurídica da situação patrimonial, tanto sua como beneficiário, quanto a UFPA, como cessionária, sem alterar a situação ambiental, urbanística e social da região.

\section{Material e Método}

Caracterização da área de estudo

A gleba C do Campus Belém da Universidade Federal do Pará (Cidade Universitária Prof. José da Silveira Netto), apresentada na Figura 1, tem área total de $1,91 \mathrm{~km}^{2}$ e engloba Guamá, a Terra Firme e o Marco. Esses bairros estão entre os 10 mais populosos no município de Belém, com 94.610 habitantes $(6,79 \%$ do total), 61.439 habitantes $(4,41 \%$ do total $)$ e 65.844 habitantes $(4,73 \%$ do total), respectivamente (IBGE, 2011).

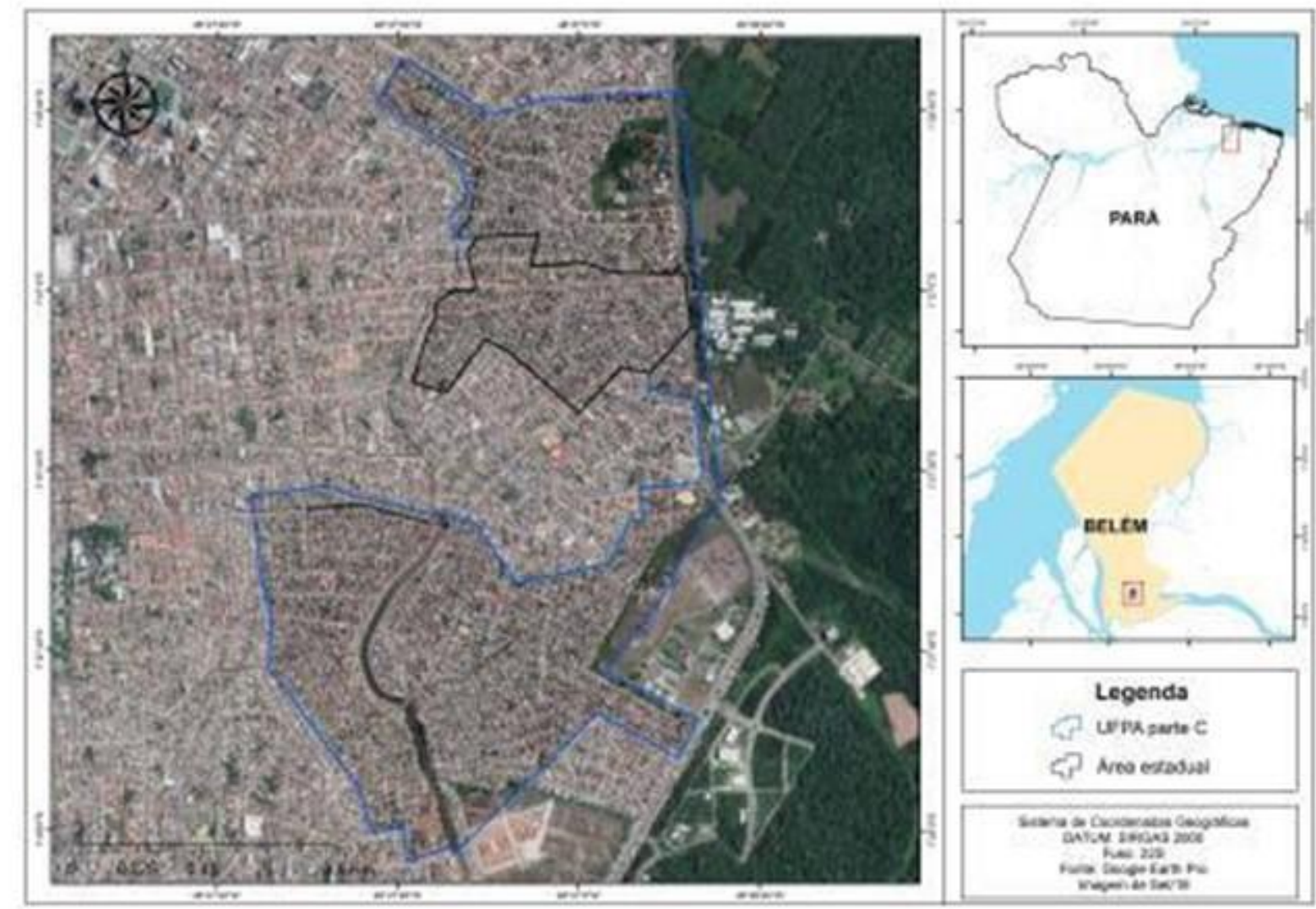

Figura 1. Mapa da gleba C da Universidade Federal do Pará. 
Belém coaduna quatro situações que concorrem para a ocorrência de elevação dos níveis de águas dos corpos hídricos, especialmente na área de estudo: a precipitação intensa, o relevo, infraestrutura de drenagem das águas pluviais e a urbanização. A questão ambiental na gleba $\mathrm{C}$ da Universidade também é pontuada nesta caracterização, trazendo a tona a suscetibilidade de inundações que a área apresenta, de acordo com a Ministério de Minas e Energia (MME, 2014).
A propensão de ocorrência desse evento, conforme Figura 2, é alta em $40,31 \%$ da área $(0.77$ $\left.\mathrm{km}^{2}\right)$, média em $38,74 \%\left(0,74 \mathrm{~km}^{2}\right)$ e baixa em $20.41 \%\left(0,39 \mathrm{~km}^{2}\right)$. Assim, a gleba é suscetível, de forma moderada a forte, a eventos de alagamentos e inundações que, em conjunto com as condições socioeconômicas da população estudada, afetam a sua capacidade de resposta a fenômenos ambientais, configurando sua vulnerabilidade socioambiental.

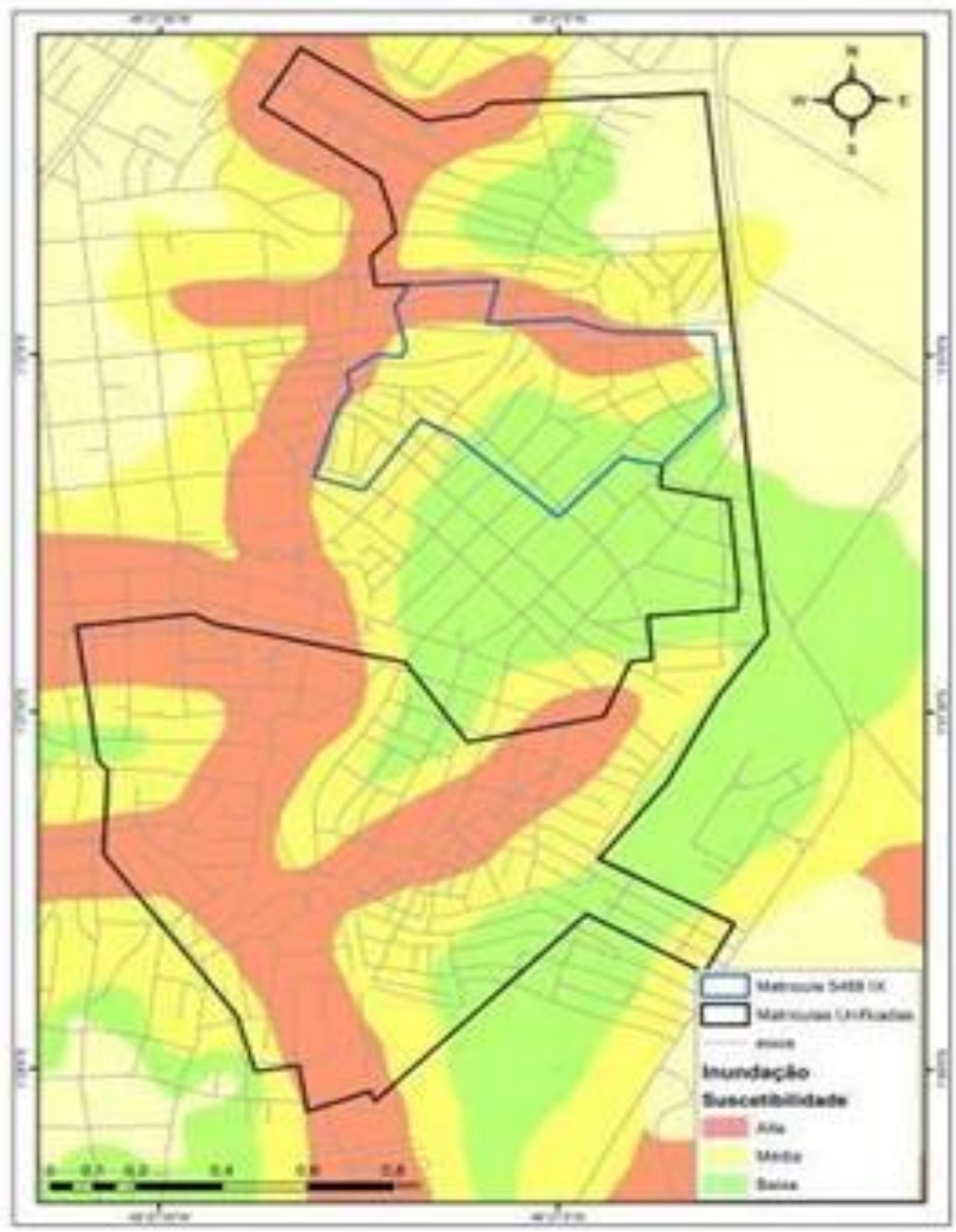

Figura 2. Mapa da Suscetibilidade à Inundação na região da gleba "C" da UFPA. Fonte': Adaptado de MME, 2014.

1 O resultado não chega a $100 \%$ em virtude dos dados não abrangerem o total da área, deixando sem informação de inundação $0.54 \%$ do território estudado $\left(0,01 \mathrm{~km}^{2}\right)$. 
Indicadores e índices de vulnerabilidade socioambiental

Os indicadores têm a função de traduzir processos complexos em informações mais simples, significativas e representativas para entender o grau de complexidade dos problemas decorrentes da interação entre a sociedade e o meio ambiente (Fenzl e Machado, 2009). Nas palavras de Vasconcelos, Cândido e Freire (2019), "para a análise de problemas complexos como é o caso da vulnerabilidade socioambiental, se deve pensar na utilização de indicadores que possam estar interligados e que agreguem várias informações que possam retratar o mais próximo possível uma realidade".

Para indicar a situação socioambiental da área objeto da pesquisa antes e após o processo de titulação para uso da terra, este trabalho utilizou indicadores e índices para montar um Índice de Vulnerabilidade Socioambiental. A utilização de componentes socioeconômicas, de infraestrutura urbana, ambientais, de saúde e de segurança na construção do IVSA constitui uma combinação que representa bem a vulnerabilidade socioambiental (Malta, Costa e Magrini, 2017). Para isso, foram adotados os indicadores referentes ao Índice de Vulnerabilidade Social - IVS, aplicado pelo Instituto de Pesquisa Econômica Aplicada - IPEA (Costa e Marguti, 2015), além de indicadores e índices jurídicos e ambientais para construção completa da análise da vulnerabilidade socioambiental, conforme apresentado na Tabela 1 .

Tabela 1. Índices e Indicadores de Vulnerabilidade Socioambiental utilizados para cálculo do IVSA

\begin{tabular}{|c|c|c|}
\hline Índice & Indicador & Descrição \\
\hline $\begin{array}{l}\text { Índice de } \\
\text { Infraestrutura } \\
\text { Urbana }\end{array}$ & $\begin{array}{c}\text { I1 - Percentual de pessoas em domicílios com } \\
\text { abastecimento de água e esgotamento sanitário } \\
\text { inadequados }\end{array}$ & $\begin{array}{c}\text { Razão entre o número de pessoas que vivem em } \\
\text { domicílios cujo abastecimento de água não provém de } \\
\text { rede geral e cujo esgotamento sanitário não é realizado } \\
\text { por rede coletora de esgoto ou fossa séptica, e a } \\
\text { população total residente em domicílios particulares } \\
\text { permanentes. }\end{array}$ \\
\hline $\begin{array}{l}\text { Índice de } \\
\text { Infraestrutura } \\
\text { Urbana }\end{array}$ & $\begin{array}{l}\text { I2 - Percentual da população que vive em domicílios } \\
\text { urbanos sem serviço de coleta de lixo }\end{array}$ & $\begin{array}{c}\text { Razão entre a população que vive em domicílios sem } \\
\text { coleta de lixo e a população total residente em domicílios } \\
\text { particulares } \\
\text { permanentes, localizados em área urbana. }\end{array}$ \\
\hline $\begin{array}{l}\text { Índice de } \\
\text { Infraestrutura } \\
\text { Urbana }\end{array}$ & $\begin{array}{c}\text { I3 - Percentual de pessoas que vivem em domicílios com } \\
\text { renda per capita inferior a meio salário mínimo e que } \\
\text { gastam mais de uma hora até o trabalho no total de } \\
\text { pessoas ocupadas, vulneráveis e que retornam } \\
\text { diariamente do trabalho. }\end{array}$ & $\begin{array}{l}\text { Razão entre o número de pessoas ocupadas, de } 10 \text { anos } \\
\text { ou mais de idade, que vivem em domicílios vulneráveis à } \\
\text { pobreza e que gastam mais de uma hora em deslocamento } \\
\text { até o local de trabalho, e o total de pessoas ocupadas } \\
\text { nessa faixa etária que vivem em domicílios vulneráveis à } \\
\text { pobreza e que retornam diariamente do trabalho. }\end{array}$ \\
\hline $\begin{array}{l}\text { Índice de } \\
\text { Capital } \\
\text { Humano }\end{array}$ & I4 - Mortalidade até um ano de idade & $\begin{array}{c}\text { Número de crianças que não deverão sobreviver ao } \\
\text { primeiro ano de vida, em cada mil crianças nascidas } \\
\text { vivas. }\end{array}$ \\
\hline $\begin{array}{l}\text { Índice de } \\
\text { Capital } \\
\text { Humano }\end{array}$ & $\begin{array}{l}\text { I5 - Percentual de crianças de } 0 \text { a } 5 \text { anos que não } \\
\text { frequentam a escola }\end{array}$ & $\begin{array}{l}\text { Razão entre o número de crianças de } 0 \text { a } 5 \text { anos de idade } \\
\text { que não frequentam creche ou escola, e o total de crianças } \\
\text { nesta faixa etária. }\end{array}$ \\
\hline $\begin{array}{l}\text { Índice de } \\
\text { Capital } \\
\text { Humano }\end{array}$ & $\begin{array}{l}\text { I6 - Percentual de pessoas de } 6 \text { a } 14 \text { anos que não } \\
\text { frequentam a escola }\end{array}$ & $\begin{array}{l}\text { Razão entre o número de pessoas de } 6 \text { a } 14 \text { anos que não } \\
\text { frequentam a escola, e o total de pessoas nesta faixa etária }\end{array}$ \\
\hline $\begin{array}{l}\text { Índice de } \\
\text { Capital } \\
\text { Humano }\end{array}$ & $\begin{array}{l}\text { I7 - Percentual de mulheres de } 10 \text { a } 17 \text { anos de idade que } \\
\text { tiveram filhos }\end{array}$ & $\begin{array}{l}\text { Razão entre o número de mulheres de } 10 \text { a } 17 \text { anos de } \\
\text { idade que tiveram filhos, e o total de mulheres nesta faixa } \\
\text { etária. }\end{array}$ \\
\hline $\begin{array}{l}\text { Índice de } \\
\text { Capital } \\
\text { Humano }\end{array}$ & $\begin{array}{l}\text { I8 - Percentual de mães chefes de família, sem } \\
\text { fundamental completo e com pelo menos um filho menor } \\
\text { de } 15 \text { anos de idade, no total de mães chefes de família. }\end{array}$ & $\begin{array}{c}\text { Razão entre o número de mulheres que são responsáveis } \\
\text { pelo domicílio, que não têm o ensino fundamental } \\
\text { completo e têm } \\
\text { pelo menos um filho de idade inferior a } 15 \text { anos morando } \\
\text { no domicílio, e o número total de mulheres chefes de } \\
\text { família. }\end{array}$ \\
\hline
\end{tabular}




\begin{tabular}{|c|c|c|}
\hline $\begin{array}{l}\text { Índice de } \\
\text { Capital } \\
\text { Humano }\end{array}$ & $\begin{array}{l}\text { I9 - Taxa de analfabetismo da população de } 15 \text { anos ou } \\
\text { mais de idade. }\end{array}$ & $\begin{array}{l}\text { Razão entre a população de } 15 \text { anos ou mais de idade que } \\
\text { não sabe ler nem escrever um bilhete simples, e o total de } \\
\text { pessoas. }\end{array}$ \\
\hline $\begin{array}{l}\text { Índice de } \\
\text { Capital } \\
\text { Humano }\end{array}$ & $\begin{array}{l}\text { I10 - Percentual de crianças que vivem em domicílios em } \\
\text { que nenhum dos moradores tem o ensino fundamental } \\
\text { completo. }\end{array}$ & $\begin{array}{c}\text { Razão entre o número de pessoas de até } 14 \text { anos que } \\
\text { vivem em domicílios em que nenhum dos moradores tem } \\
\text { o ensino fundamental completo, e a população total nesta } \\
\text { faixa etária residente em domicílios particulares } \\
\text { permanentes }\end{array}$ \\
\hline $\begin{array}{l}\text { Índice de } \\
\text { Capital } \\
\text { Humano }\end{array}$ & $\begin{array}{l}\text { I11 - Percentual de pessoas de } 15 \text { a } 24 \text { anos que não } \\
\text { estudam, não trabalham e possuem renda domiciliar per } \\
\text { capita igual ou inferior a meio salário mínimo, na } \\
\text { população total dessa faixa etária. }\end{array}$ & $\begin{array}{l}\text { Razão entre as pessoas de } 15 \text { a } 24 \text { anos que não estudam, } \\
\text { não trabalham e são vulneráveis à pobreza, e a população } \\
\text { total nesta faixa etária. }\end{array}$ \\
\hline $\begin{array}{l}\text { Índice de } \\
\text { Renda e } \\
\text { Trabalho }\end{array}$ & $\begin{array}{l}\text { I12 - Proporção de pessoas com renda domiciliar per } \\
\text { capita igual ou inferior a meio salário mínimo. }\end{array}$ & $\begin{array}{c}\text { Proporção dos indivíduos com renda domiciliar per capita } \\
\text { igual ou inferior ao } \\
\text { equivalente a meio salário mínimo. }\end{array}$ \\
\hline $\begin{array}{l}\text { Índice de } \\
\text { Renda e } \\
\text { Trabalho }\end{array}$ & $\begin{array}{l}\text { I13 - Taxa de desocupação da população de } 18 \text { anos ou } \\
\text { mais de idade. }\end{array}$ & $\begin{array}{l}\text { Percentual da população economicamente ativa (PEA) } \\
\text { nessa faixa } \\
\text { etária que estava desocupada. }\end{array}$ \\
\hline $\begin{array}{l}\text { Índice de } \\
\text { Renda e } \\
\text { Trabalho }\end{array}$ & $\begin{array}{l}\text { I14 - Percentual de pessoas de } 18 \text { anos ou mais sem } \\
\text { fundamental completo e em ocupação informal }\end{array}$ & $\begin{array}{l}\text { Razão entre as pessoas de } 18 \text { anos ou mais sem } \\
\text { fundamental completo, em ocupação informal, e a } \\
\text { população total nesta faixa etária. }\end{array}$ \\
\hline $\begin{array}{l}\text { Índice de } \\
\text { Renda e } \\
\text { Trabalho }\end{array}$ & $\begin{array}{l}\text { I15 - Percentual de pessoas em domicílios com renda per } \\
\text { capita inferior a meio salário mínimo e dependentes de } \\
\text { idosos. }\end{array}$ & $\begin{array}{l}\text { Razão entre as pessoas que vivem em domicílios } \\
\text { vulneráveis à pobreza e nos quais a renda de moradores } \\
\text { idosos corresponde a mais da metade do total da renda } \\
\text { domiciliar, e a população total residente em domicílios } \\
\text { particulares permanentes. }\end{array}$ \\
\hline $\begin{array}{l}\text { Índice de } \\
\text { Renda e } \\
\text { Trabalho }\end{array}$ & $\begin{array}{l}\text { I16 - Taxa de atividade das pessoas de } 10 \text { a } 14 \text { anos de } \\
\text { idade. }\end{array}$ & $\begin{array}{l}\text { Razão das pessoas de } 10 \text { a } 14 \text { anos de idade que eram } \\
\text { economicamente ativas, ou seja, que estavam ocupadas } \\
\text { ou desocupadas na semana de referência do censo entre o } \\
\text { total de pessoas nesta faixa etária. }\end{array}$ \\
\hline $\begin{array}{l}\text { Índice } \\
\text { Jurídico }\end{array}$ & $\begin{array}{l}\text { I17 - Percentual de imóveis participantes (cadastrados } \\
\text { válidos) do programa, mas sem o reconhecimento da } \\
\text { CUEM }\end{array}$ & $\begin{array}{c}\text { Razão entre o número de famílias que foram cadastrados } \\
\text { para regularização fundiária e que não tiveram } \\
\text { reconhecimento da CUEM }\end{array}$ \\
\hline $\begin{array}{l}\text { Índice } \\
\text { Jurídico }\end{array}$ & $\begin{array}{l}\text { I18 - Percentual de moradores com CUEM não } \\
\text { registrada em Cartório de Imóveis }\end{array}$ & $\begin{array}{c}\text { Razão entre das famílias que obtiveram o reconhecimento } \\
\text { da concessão porém não tiveram seus títulos registrados } \\
\text { em Cartório de Imóveis }\end{array}$ \\
\hline $\begin{array}{l}\text { Índice de } \\
\text { Saúde e Meio } \\
\text { Ambiente }\end{array}$ & $\begin{array}{l}\text { I19 - Ocorrência de precipitação diária igual ou acima de } \\
20 \mathrm{~mm}\end{array}$ & $\begin{array}{l}\text { Número de ocorrências de precipitação igual ou acima de } \\
\qquad 20 \mathrm{~mm}\end{array}$ \\
\hline $\begin{array}{l}\text { Índice de } \\
\text { Saúde e Meio } \\
\text { Ambiente }\end{array}$ & $\begin{array}{c}\text { I20 - Notificações oficiais de ocorrência de, pelo menos, } \\
\text { um caso de doença de veiculação hídrica (Hepatite } \\
\text { infecciosa, Leptospirose, Doença diarreica, Dengue e } \\
\text { Esquistossomose) }\end{array}$ & $\begin{array}{l}\text { Percentual de moradores internados pela ocorrência de, } \\
\text { pelo menos, um caso de doença de veiculação hídrica. }\end{array}$ \\
\hline $\begin{array}{l}\text { Índice de } \\
\text { Saúde e Meio } \\
\text { Ambiente }\end{array}$ & I 21 - Percentual de arborização na área. & Percentual de arborização na área pesquisada. \\
\hline
\end{tabular}

Fonte: Com adaptações a partir de Costa e Marguti (2015).

Explicando o significado de cada índice compositor do IVS, Costa e Marguti (op. cit.) explicam que o Índice de Infraestrutura Urbana procura refletir as condições de acesso aos serviços de saneamento básico e de mobilidade urbana, dois aspectos relacionados ao lugar de domicílio das pessoas e que impactam significativamente seu bemestar. O sub-índice referente ao capital humano envolve dois aspectos (ou ativos e estruturas) que determinam as perspectivas (atuais e futuras) de inclusão social dos indivíduos: saúde e educação. Por fim, a vulnerabilidade de renda e trabalho, 
medida pelo sub-índice respectivo, agrupa não só indicadores relativos à insuficiência de renda (considerando o ano de 2010 - último censo), mas incorpora outros fatores que, associados ao fluxo de renda, configuram um estado de insegurança de renda.

O Índice Jurídico ora proposto visa conhecer a relação teoria-prática do que foi proposto para regularização e o que foi realizado na área da Gleba C. O indicador $\mathrm{I} 17$ refletirá quantos atos jurídicos foram aperfeiçoados, ou seja, quantas CUEMs geraram os efeitos de direito real de uso do bem público como, por exemplo, a segurança contra despejos forçados. O indicador I18 é essencial para conhecermos a razão entre o número de pessoas cadastradas nos projetos e as que foram beneficiadas com os respectivos títulos de CUEM e assim, montando o índice correspondente, relacionar qual(is) o(s) impedimento(s) não foi(ram) superado(s) e que dificultaram a abrangência de um maior número de pessoas.

Quanto ao Índice de Saúde e Meio Ambiente, as infraestruturas urbanísticas e de saneamento básico da área são importantes para prevenir e/ou mitigar os impactos de alagamento e/ou inundação, porém a precipitação diária também deve ser registrada pois também influencia na ocorrência desses eventos. O indicador I19 terá como parâmetro a precipitação diária acumulada de 20 mm em 24 horas, informação essa observada todos os dias às $12 \mathrm{~h}$ UTC (9h em Belém). Esse valor Tabela 2. Fontes dos dados utilizados para o cálculo do IVSA

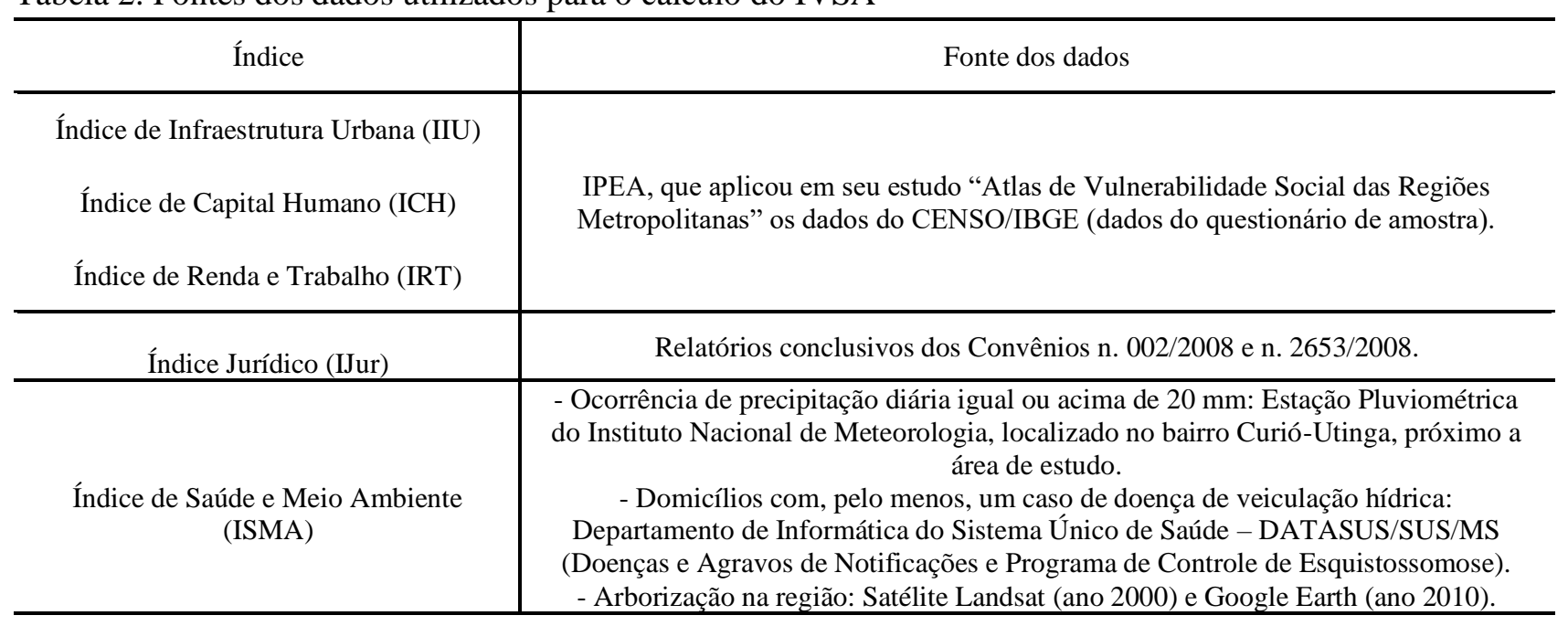

mínimo é usado nos estudos de Campos, Mota \& Santos (2015) e Pontes et al (2017) para pesquisa da influência da precipitação para formação de pontos de alagamentos no ambiente urbano.

O município de Belém registra, anualmente, altos índices pluviométricos, já relatados em tópico pertinente e, quando essas estruturas não são adequadas ou mal gerenciadas, a população fica mais vulnerável ao risco de contrair doenças relacionadas ao saneamento ambiental inadequado DRSAI, cujos dados serão relacionados ao indicador I20. Foram escolhidas 5 doenças para coleta e uso de dados para construção do indicador: Duas doenças de transmissão feco-oral (doenças diarreicas e hepatite infecciosa ou hepatite A), uma doença transmitida por inseto vetor (dengue) e duas doenças transmitidas através de contato com a água (esquistossomose e leptospirose).

Também relacionado à infraestrutura urbana, a arborização é muito importante na prevenção e/ou mitigação dos impactos da precipitação em uma área suscetível a inundação, pois ajudar a deter e/o reter a água pluvial e diminuir a velocidade do runoff, interferindo diretamente no ciclo hidrológico e, por isso, sua existência será pesquisada no indicador I21.

Os dados obtidos e analisados nesta pesquisa são cononantes com os períodos censitários do país. Para o cálculo dos indicadores e índices, foram utilizados os dados conforme Tabela 2.
Cálculo do índice de vulnerabilidade socioambiental

Em geral, todos os indicadores têm a mesma relação com o índice correspondente. Sendo assim, em regra, todos os indicadores devem ter o mesmo peso, para que todos os índices, ao final, tenham o peso 1, porém algumas alterações foram necessárias nos indicadores em virtude da abrangência e ano dos dados utilizados, conforme apresentado na Tabela 3 , a seguir. 


\begin{tabular}{|c|c|c|}
\hline Indice & Indicador & Peso \\
\hline \multirow{3}{*}{ IIU } & I1 & 0,3 \\
\cline { 2 - 3 } & I2 & 0,3 \\
\cline { 2 - 3 } & I3 & 0,4 \\
\hline \multirow{7}{*}{ ICH } & I4 & 0,125 \\
\cline { 2 - 3 } & I5 & 0,125 \\
\cline { 2 - 3 } & I6 & 0,125 \\
\cline { 2 - 3 } & I7 & 0,125 \\
\cline { 2 - 3 } & I8 & 0,125 \\
\cline { 2 - 3 } & I9 & 0,125 \\
\cline { 2 - 3 } & I10 & 0,125 \\
\cline { 2 - 3 } & I11 & 0,125 \\
\hline
\end{tabular}

Tabela 3. Peso dos indicadores componentes do IVSA. Fonte: Com adaptações, a partir de Costa e Marguti (2015).

Para tornar a análise e comparação entre os indicadores mais eficiente, foi criada a seguinte convenção no trabalho: o limite mínimo de qualquer indicador é 0 (o melhor valor) e o limite máximo é 1 (o pior valor). Desta forma, todos os indicadores passam a estar na mesma escala adimensional e podem ser comparados mais facilmente. A forma de cálculo geral do valor dos indicadores é descrita na equação 1:

Indicador $=\frac{(V O-P V)}{(M V-P V)}(1)$

Em que:

$\mathrm{VO}=$ Valor Observado

$\mathrm{PV}=$ Pior Valor

$\mathrm{MV}=$ Melhor Valor

Importa salientar que existem exceções a essa regra. Para os indicadores I17 e I18, o cálculo é realizado de acordo com as equações 2 e 3, apresentadas a seguir, respectivamente.

$$
\begin{aligned}
& \mathrm{I} 17=\frac{\left(\frac{\text { CUEMSEmitidas }}{\text { ImoveiscomCadastroValido }}\right)-1}{0-1}(2) \\
& \mathrm{I} 18=\frac{\left(\frac{\text { CUEMSRegistradasemCartorio }}{\text { CUEMSEmitidas }}\right)-1}{0-1}(3)
\end{aligned}
$$

Para o indicador de doenças de veiculação hídrica (I120), duas fórmulas foram utilizadas, sendo uma delas considerando o peso de cada doença pesquisada. Para chegar ao valor de cada doença de veiculação hídrica pesquisada, o cálculo seguiu a fórmula geral (equação 4) e, após sua aplicação, o

\begin{tabular}{|c|c|c|}
\hline Indice & Indicador & Peso \\
\hline \multirow{4}{*}{ IRT } & I12 & 0,2 \\
\cline { 2 - 3 } & I13 & 0,2 \\
\cline { 2 - 3 } & I14 & 0,2 \\
\cline { 2 - 3 } & I15 & 0,2 \\
\cline { 2 - 3 } & I16 & 0,2 \\
\hline \multirow{3}{*}{ Jur } & I17 & 0,5 \\
\cline { 2 - 3 } & I18 & 0,5 \\
\hline \multirow{3}{*}{ ISMA } & I19 & 0,4 \\
\cline { 2 - 3 } & I20 & 0,2 \\
\cline { 2 - 3 } & I21 & 0,4 \\
\hline
\end{tabular}

valor final do indicador 20 é obtido a partir da equação 5.

$$
\text { Indicador doença }=\frac{(\text { Vobruto }- \text { PVbruto })}{(\text { MVbruto }- \text { PVbruto })}(4)
$$

Em que:

VObruto $=$ Valor Observado bruto

PVbruto $=$ Pior Valor bruto

MVbruto $=$ Melhor Valor bruto

$$
\mathrm{I} 20=
$$

$\left(\frac{(I H .0,04)+(I L .0,04)+(I D D .0,04)+(I D .0,04)+(I E .0,04)}{0,2}\right)(5)$

Em que:

$\mathrm{IH}=$ Indicador de hepatite infecciosa

$\mathrm{IL}=$ Indicador de leptospirose

IDD = Indicador de doença diarreica

ID $=$ Indicador de dengue

$\mathrm{IE}=$ Indicador de esquistossomose

Por fim, o indicador I21, como o valor alto do indicador representa uma situação de menor vulnerabilidade, a equação geral é alterada no numerador, da seguinte forma (equação 6):

$\mathrm{I} 21=\frac{(M V-V O)}{(M V-P V)}(6)$

Um índice pode ser formado por um ou mais indicadores. Como os indicadores estão em uma mesma escala, estes podem ser envolvidos em operações aritméticas. Para os índices, o calculado usa a média ponderada dos indicadores respectivamente agrupados, tais como vistos na Tabela 4: 
Tabela 4. Equações para cálculo dos Índices.

\begin{tabular}{cc}
\hline Índice & Cálculo \\
\hline IIU & $\frac{(I 1 . P 1)+(I 2 . P 2)+(I 3 . P 3)}{(P 1+P 2+P 3)}$ \\
ICH & $\frac{(I 4 . P 4)+(I 5 . P 5)+(I 6 . P 6)+(I 7 . P 7)+(I 8 . P 8)+(I 9 . P 9)+(I 1 . P 10)+(I 11 . P 11)}{(P 4+P 5+P 6+P 7+P 8+P 9+P 10+P 11)}$ \\
IRT & $\frac{(I 12 . P 12)+(I 13 . P 13)+(I 14 . P 14)+(I 15 . P 15)+(I 16 . P 16)}{(P 12+P 13+P 14+P 15+P 16)}$ \\
IJur & $\frac{(I 17 . P 17)+(I 18 . P 18)}{(P 18+P 19)}$ \\
ISMA & $\frac{(I 19 . P 19)+(I 20 . P 20)+(I 21 . P 21)}{(P 19+P 20+P 21)}$ \\
\hline
\end{tabular}

O cálculo do Índice de Vulnerabilidade Socioambiental é a média aritmética de todos os índices a serem calculados, na forma apresentada na equação 7 :

$$
I V S A=\frac{I I U+I C H+I R T+I J u r+I S M A}{5}(7)
$$

Os indicadores e índices foram calculados de forma que o resultado variasse entre os valores 0 e 1 , sendo 0 a melhor situação (vulnerabilidade muito baixa) e 1, a pior (vulnerabilidade muito alta). Para este trabalho, será feita uma adaptação da leitura dos resultados dos indicadores e índices, conforme Figura 3, resumindo em graus de vulnerabilidade baixo, média e alto.

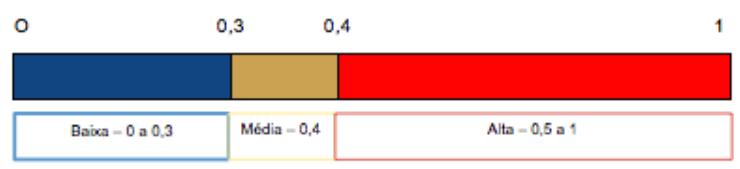

Figura 3. Faixas de IVSA para esta pesquisa. Fonte: Adaptado de Costa e Marguti (2015).
Após esta etapa, os indicadores padronizados foram transferidos para um mapa de vulnerabilidade. A elaboração de mapas baseados nos resultados estimados pelo índice constitui um ponto positivo, uma vez que, de acordo com Malta, Costa e Magrini (2017), a elaboração de um mapaíndice para o IVSA favorece a visualização de aspectos importantes dos processos de vulnerabilidade.

\section{Resultados e discussão}

Para os indicadores I1, I2 e I3, o ano de 2010 apresentam melhores resultados, quando comparados aos resultados do ano 2000 (Figura 4). Nos dois anos pesquisados, os valores são baixos, o que nos indica que poucos moradores ainda não dispõem de infraestrutura básica para sua vivência e deslocamento.

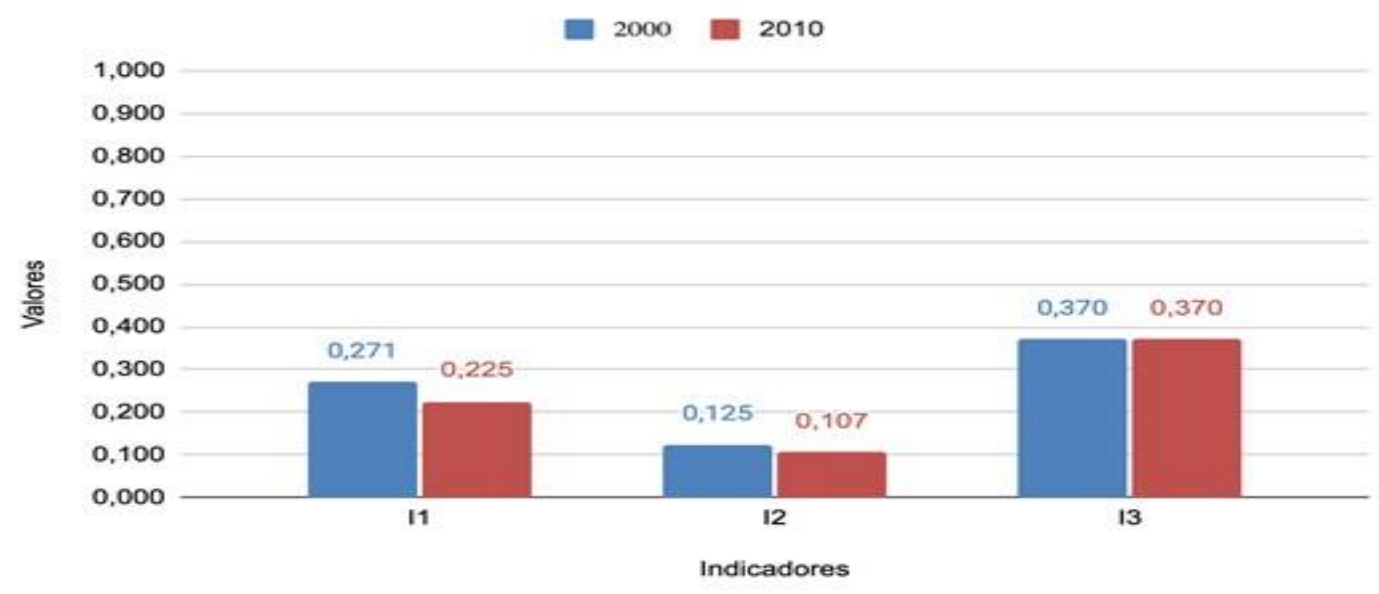

Figura 4. Indicadores I1, I2 e I3 para os anos pesquisados para a Gleba C. 
A ocupação irregular da gleba foi consequência, décadas antes, de ações higienistas e estéticas do Poder Público, que pressionou a ocupação de áreas de várzea por quem buscava moradia e que não conseguia fixar-se no centro da cidade. Em Belém e região, as áreas precárias e alagáveis, de baixas cotas altimétricas e habitadas por populações pobres, são conhecidas como baixadas (Silva e Rocha, 2019). Como reflexo, temse uma quantidade considerável de pessoas com renda baixa. Dentre seus moradores com 10 anos ou mais que apresentam rendimentos, a maioria apresenta renda entre meio e um salário mínimo (IBGE, 2011).

Esse uso e ocupação do espaço está diretamente relacionada com a falta de infraestrutura básica de saneamento, apesar da melhoria dos indicadores relacionados. Os bairros abrangidos pela gleba C, de uma forma geral, são atendidos por serviços de rede geral de abastecimento de água e coleta de lixo (89,02\% - Guamá; 82,57\% - Marco; 93,64\% - Terra Firme; IBGE, 2011). Contextualizando os resultados do I1 e I2, encontrase a execução de projetos de saneamento básico na região, na bacia do Tucunduba (macrodrenagem da bacia e saneamento integrado da bacia). O Projeto de Recuperação e Urbanização da Bacia do Tucunduba, de 1999, tinha como objetivo a recuperação do igarapé e de seu entorno. A posteriori, em 2008, o governo do estado lançou o Projeto de Saneamento Integrado da Bacia do Tucunduba, projeto esse integrante do Programa de Aceleração do Crescimento - PAC, objetivando a implantação de infraestrutura urbana na área, com sistema viário, abastecimento de água, esgotamento sanitário, saneamento e construção de unidades habitacionais (Santos, 2010).

Em relação aos indicadores sobre o Índice de Capital Humano (Figura 5) e Índice de Renda e Trabalho (Figura 6), de uma forma geral, a área da parte C da UFPA apresentou redução nos valores relativos aos indicadores pesquisados, o que nos apresenta que a área apresentou melhoria estrutural e para a população, em questão de escolaridade e renda, que apresentam relação direta: No Brasil, Langoni (1973 citado por Pinto, 2017) foi um dos precursores em aferir a contribuição da educação nas diferenças individuais de renda; em seu estudo ele analisa que a variável educação explica $1 / 3$ do valor da renda de um indivíduo e pessoas com nível superior completo tem um aumento de mais de 50\% na sua renda, enquanto analfabetos permanecem com sua renda inalterada.

Os indicadores de renda e trabalho são resultado da economia brasileira, que alcançou crescimento médio anual próximo a $4 \%$ a.a. entre 2000 e 2011, valor superior ao observado nas duas décadas anteriores, que foi cerca de $2 \%$ anuais (Cruz et. al., 2012). Apenas os indicadores I15 e I16 apresentaram desempenho inverso aos outros indicadores. Ainda que a dependência de renda domiciliar do idoso tenha aumentado (I16), não significa necessariamente que existem menos pessoas trabalhando (vide resultados do indicador I13) ou ganhando menos (vide resultados do indicador I12), e sim que os trabalhadores tenham ficado mais velhos e chegado a idade idosa. Essa população mais velha é consequência do aumento da expectativa de vida no município de Belém, que de 70,5 anos em 2000, passou a 74,3 em 2010 (PNUD, IPEA e FJP, 2013).

Em relação aos indicadores jurídicos (Figura 7), os valores encontrados ficam no conjunto de alta vulnerabilidade pois, mesmo com o trabalho feito pela UFPA, poucos moradores foram contemplados pelo título (I17) e/ou tiveram seus títulos de Concessão de Uso Especial para Fins de Moradia registradas em Cartório de Registro de Imóveis (I18). 
Revista Brasileira de Geografia Física v.14, n.02 (2021) 2322-2337.

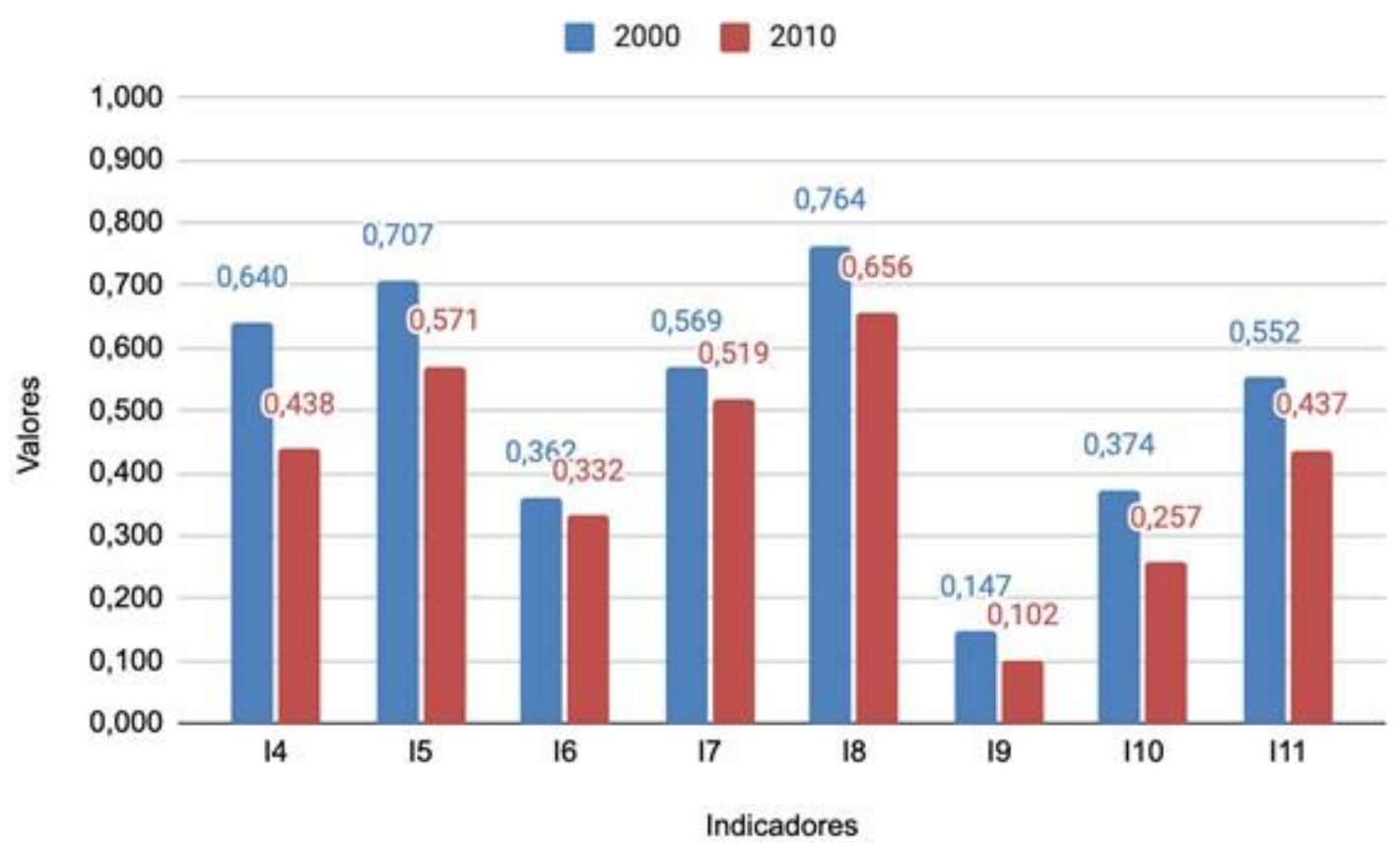

Figura 5. Indicadores relativos ao Índice de Capital Humano para os anos pesquisados na Gleba C.

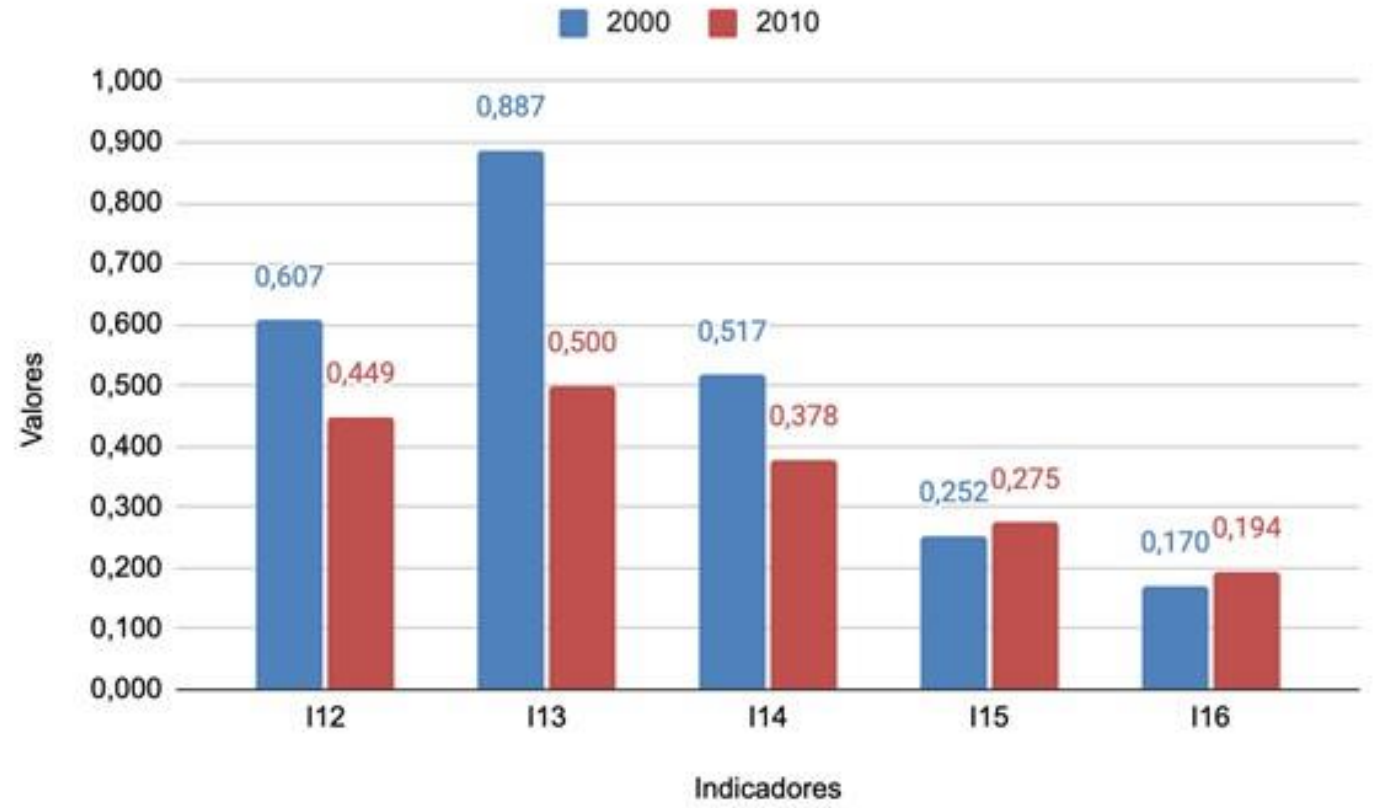

Figura 6. Indicadores relativos ao Índice de Renda e Trabalho para os anos pesquisados na Gleba C. 


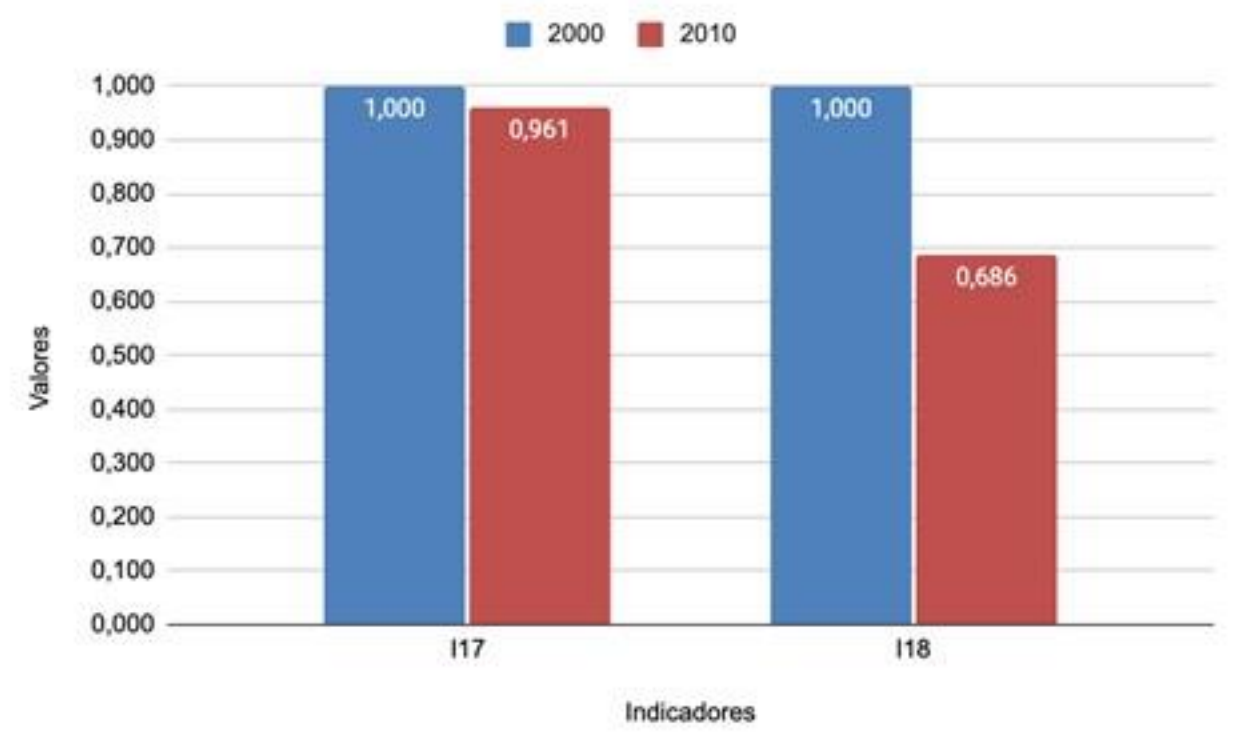

Figura 7. Indicadores do Índice Jurídico para os anos pesquisados na Gleba C.

Dentre alguns fatores que podem ser elencados para explicar tal resultado, temos o pouco tempo de trabalho realizado: As ações da CRF/UFPA foram realizadas entre 11/11/2008 à 06/11/2009, a partir da assinatura de convênio $\mathrm{n}$. 002/2008, entre a Secretaria de Estado de Desenvolvimento Urbano e Regional do Estado do Pará - SEDURB - e a Universidade, tendo o Instituto de Terras do Pará - ITERPA - como parceiro. Esse convênio foi realizado após o destaque e transmissão de $563.970 \mathrm{~m}^{2}$, ou seja, 33\% de área da gleba $\mathrm{C}$ ao Estado (CARDOSO et al., 2014). Nessa etapa, foram realizados 2001 cadastros socioeconômicos, sendo $98 \%$ dos imóveis cadastros são de uso residencial (1970 imóveis residenciais) (UFPA, 2010). Em diligência ao Cartório de Registro de Imóveis do $2^{\circ}$ Ofício do Município, responsável pelos registros na área de estudo, até o final de 2010, foram registrados 279 CUEMs (BELÉM, 2018), ou seja, um pouco mais de 7\%.

A partir de 2010, os trabalhos da CRF/UFPA foram realizados na outra porção da gleba, em conjunto com a Superintendência do Patrimônio da União - SPU (contrato n. 2653), o que não pôde ser mensurado em sua totalidade nessa pesquisa, visto que, até o dezembro de 2010, nenhum morador havia recebido o título registrado (UFPA, 2011).

Além do período de trabalho, outro fator para que poucos moradores fossem titulados foi a falta de preenchimento de informações básicas, como documentos pessoais do responsável (RG, CPF, certidões), e a impossibilidade de regularização do imóvel, por falta de cumprimento dos requisitos legais.
No relatório do Convênio 002/2008, dos 1.621 imóveis com cadastros válidos, 786 (48\%) estavam com documentação pendente. Dos documentos pendentes, $35 \%$ estão declarações que podem ser emitidas pelo próprio morador (declarações de renda, endereço e união estável, para suprir a ausência de comprovantes formais). De acordo com a CRF/UFPA, "pode ser considerado desinteresse do mesmo, seja por problemas conjugais e/ou judiciais diversos ou por descrédito nas ações públicas ou do projeto, por muitas vezes relatadas durante as ações de sensibilização e orientação na área" (UFPA, 2011). Outra informação importante sobre a parte documental é que $29 \%$ dos imóveis sem qualquer documentação disponibilizada (Registro Geral, Cadastro de Pessoa Física e Certidão de Nascimento/Casamento, além das declarações supra).

Já sobre o registro, a demora não ocorria por parte dos moradores, e sim do trâmite entre o órgão responsável (ITERPA ou SPU) e o Cartório de Registro de Imóveis, visto que o morador recebia o título, à época, somente após a realização desse registro.

Os indicadores formadores do Índice de Saúde e Meio Ambiente apresentam resultados diversos (Figura 8): Em relação ao indicador I19, houve um aumento na ocorrência de precipitação diária acima de $20 \mathrm{~mm}$ entre 2000 e 2010. Campos, Mota e Santos (2015) e Pontes et al. (2017) já haviam detectado em seus estudos abordando dados históricos de precipitação no município de Belém que, comparativamente a década de 1990, a década de 2000 teve maior ocorrência de eventos. 
Sobre o indicador I20, as notificações de ocorrência das doenças de veiculação hídrica pesquisadas diminuíram nos anos pesquisados, mesmo com o aumento das notificações de casos de doença diarreica. Isso apresenta relação com a ampliação do acesso à água e coleta de lixo, serviços de saneamento básico observados nos indicadores I1 e I2.
O último indicador, I21, sofreu piora entre os anos de 2000 e 2010, ou seja, a arborização na gleba diminuiu no período estudado, o que converge com a informação do Censo 2010 sobre o assunto, que destaca o município de Belém com o menor percentual de arborização dentre 15 municípios com mais de 1 milhão de habitantes, com apenas 22,4\% (IBGE, 2012).

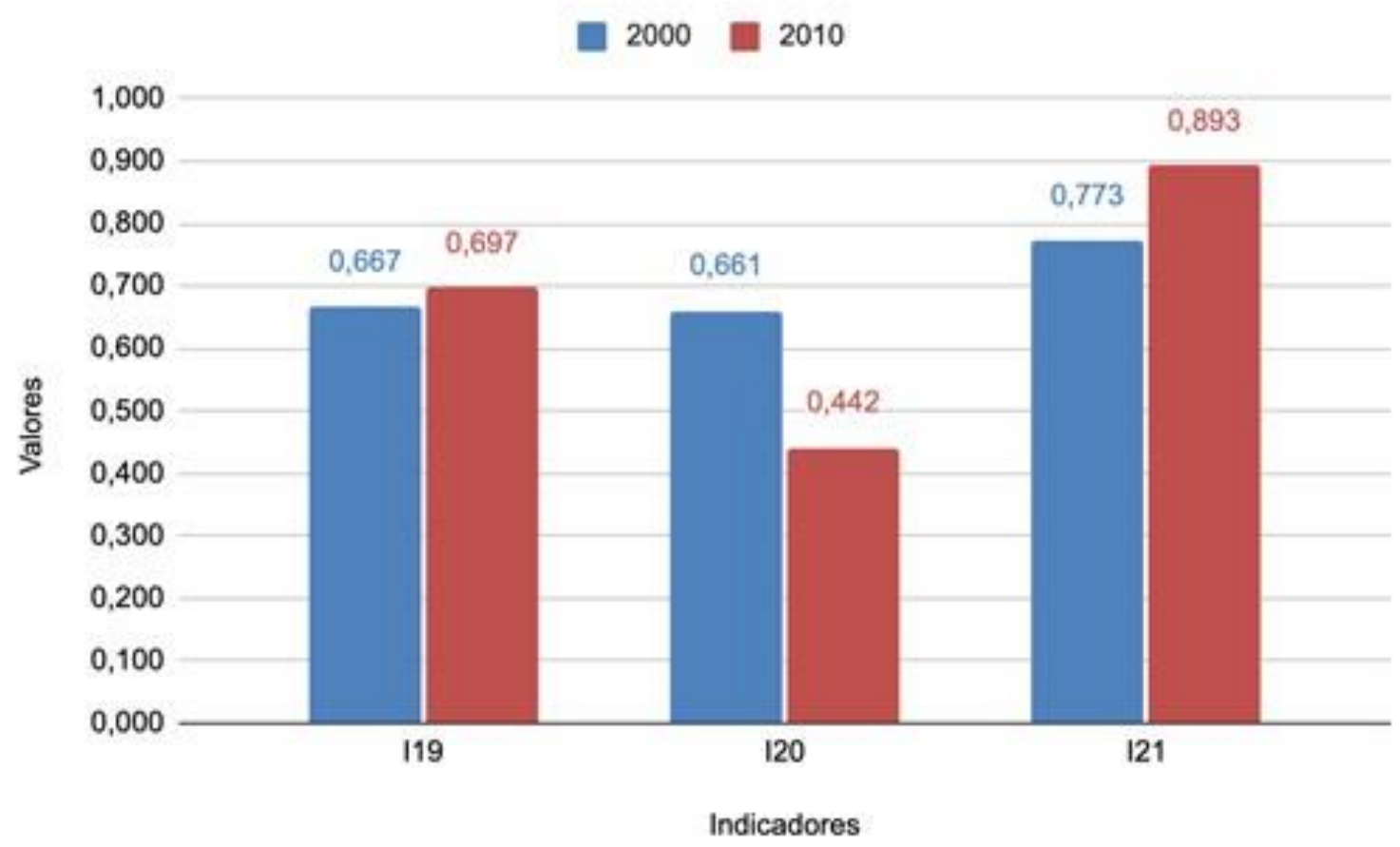

Figura 8. Indicadores do Índice de Saúde e Meio Ambiente para os anos pesquisados na Gleba C.

Usando os resultados dos indicadores e índices para cálculo do Índice de Vulnerabilidade Socioambiental, tem-se os seguintes resultados: Em 2000, o IVSA foi de 0,595 e, em 2010, o resultado foi de 0,514 , ou seja, houve uma diminuição muito pequena no grau de vulnerabilidade na gleba $\mathrm{C}$, que não modificou o quadro já apresentado em 2000: A área de estudo, sob a perspectiva do risco de alagamentos e inundações, ele está em um grau de vulnerabilidade alto, conforme mapa na Figura 9.

A gleba $\mathrm{C}$ foi beneficiada por convênios entre entes públicos estadual e federais para a titulação de CUEMs a aqueles que se enquadravam nos requisitos legais. A CUEM faz parte do rol de instrumentos de regularização fundiária de bens públicos. Apesar de estar relacionado a regularização fundiária, os resultados do IVSA da área em 2000 e 2010 mostram que o trabalho realizado não influenciou na diminuição do grau de vulnerabilidade socioambiental dos moradores.

A ocupação do solo nos grandes centros urbanos e sua regulamentação é um problema presente em diversos países. $\mathrm{O}$ crescimento desordenado das cidades e a consequente construção de edificações irregulares, na grande maioria dos casos, é resultado da política de divisão de riquezas. O trabalho efetuado pela Universidade Federal do Pará surgiu como um remédio jurídico para atender a demanda da comunidade moradora da área da gleba $\mathrm{C}$ e, consequentemente, a gestão patrimonial da instituição. 


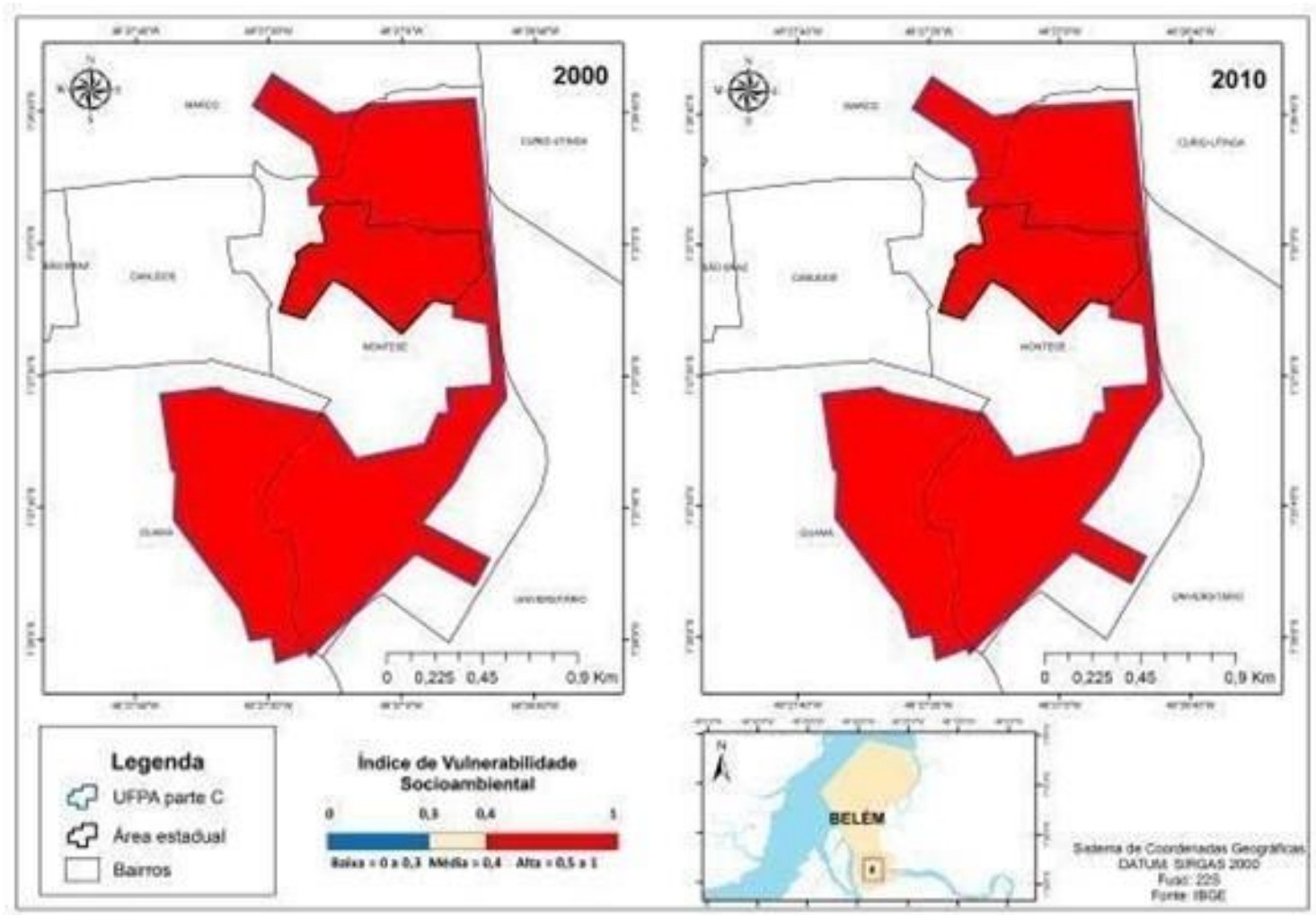

Figura 9. Mapa do grau de vulnerabilidade socioambiental para gleba C da UFPA nos anos de 2000 e 2010.

Apesar do uso do termo regularização fundiária nos títulos das atividades desenvolvidas na área, o que foi promovido pelo estado do Pará e pela UFPA, em conjunto com a SPU, foi o reconhecimento de direito real e firmação de contratos administrativos com alguns moradores da gleba $\mathrm{C}$, visto que nem todos possuíam, a época, a documentação necessária para a realização dessa etapa, que foi meramente patrimonial, de forma a auxiliar a Universidade na gestão de seu patrimônio fundiário, especialmente nessa área que fica mais distante do centro administrativo do Campus Guamá, sem necessitar retirar esses moradores e despender recursos financeiros para pagamento de benfeitorias realizadas na área por esses sujeitos.

Dar segurança da posse é importante para que o beneficiário sinta garantia, em tese, de não sofrer impedimentos, por terceiros, do exercício de seu direito, porém, existem aspectos negativos da atividade de regularização dominial, além de estimulador $\mathrm{o}$ morador a realizar melhorias $\mathrm{e}$ investimentos no imóvel. Quanto a esses aspectos, pode-se destacar o aumento demográfico na área, pois essa área apresenta, agora, um diferencial positivo em relação a outros locais, "o que, somado a condições favoráveis de localização, poderá atrair um número maior de moradores, seja por meio do aluguel de cômodos, seja em novas lajes construídas sobre as casas existentes" (Spinazzola, 2008), a não implementação de equipamentos públicos e infraestrutura básica, pela falta de áreas destinadas às suas execuções, e a consolidação de lotes privados em áreas públicas, insuflando o mercado imobiliário e os sujeitos que têm capital a ocuparem o local e estipularem suas próprias regras perante a comunidade.

Com esse conjunto de informações, observase que o trabalho realizado na gleba $\mathrm{C}$ não teve resultados mais expressivos, em relação ao grau de vulnerabilidade socioambiental, também em virtude de negligência ou falta de informação da população virtualmente beneficiária sobre seus direitos reais e/ou seus direitos de registro documental básico (certidões e registro na Polícia Civil - RG - e na Receita Federal - CPF). O relatório do contrato supra não explica a falta dos documentos pessoais básicos de determinados moradores, porém cita que o descrédito dos mesmos em relação ao projeto é responsável por $48 \%$ dos imóveis cadastrados não serem beneficiários da CUEM.

Como sugestão, um trabalho efetivo de regularização fundiária deveria envolver um conjunto de órgãos responsáveis pela área social, ambiental, urbanístico e fundiário para que, de forma concatenada e a longo prazo, realizar os trabalhos necessários para que os resultados sejam captados 
pelos indicadores e que efetivamente diminuam o grau de vulnerabilidade na área estudada.

\section{Conclusões}

O município de Belém sofreu ocupações diferenciadas de seu espaço, privilegiando áreas estratégicas e deixando as áreas de várzea serem ocupadas pela população socioeconomicamente vulnerável.

Os bairros do Guamá e Terra Firme surgiram de forma semelhante, e o bairro do Marco fez parte do planejamento e ordenamento do uso do solo da cidade, mas ainda sim tem área de ocupação de várzea. Ocupando parte desses territórios, a UFPA foi criada como estratégia para sedimentar o poder estatal na Amazônia e seu planejamento e construção do campus na capital do Pará teve como base os campi de Universidades Nacionais e Internacionais.

O tamanho da área do Campus Guamá da UFPA e as construções de suas estruturas mais centralizadas no Setor Básico e Profissional, além da falta de espaço habitacional para população socioeconomicamente vulnerável foram fatores que culminaram na ocupação, a priori, irregular da gleba C, objeto de trabalhos da UFPA quase 40 anos depois.

Apesar de estar relacionado a regularização fundiária, os resultados do IVSA da gleba $\mathrm{C}$ em 2000 e 2010 mostram que o trabalho realizado não influenciou na diminuição do grau de vulnerabilidade socioambiental dos moradores, apesar da melhoria da maioria dos indicadores estudados.

Acerca do lapso temporal estudado, faz-se importante ressalvar que os dados coletados para o ano de 2010 foram próximos ao período da realização das atividades de regularização patrimonial, iniciadas em 2008. Assim, pode ser que, nesse período de 2 (dois) anos, não haja alteração percebida nos indicadores, o que não significa que o cenário pós atividades não tenha melhorado pois, pela própria definição, os indicadores apresentam um possível cenário da realidade estudada.

Por esse motivo, esse trabalho torna-se ainda mais relevante pois ele pode ser visto como ponto de partida de estudos futuros, que podem reproduzi-lo usando outras fontes de dados, por exemplo a PNAD Contínua, realizada anualmente pelo IBGE, ou usando as mesmas fontes, especialmente a partir de 2020, com a realização do CENSO. Com novos estudos, com lapso temporal maior, os resultados desse trabalho podem ser confirmados ou rechaçados.

\section{Agradecimentos}

O primeiro autor agradece ao Programa de Pós-Graduação em Ciências Ambientais (PPGCA) da Universidade Federal do Pará, em parceria com a EMBRAPA e MPEG pela oportunidade de integrar o corpo discente do Mestrado em Ciências Ambientais.

\section{Referências}

Almeida, L. Q., 2012. Riscos ambientais e vulnerabilidades nas cidades brasileiras: conceitos, metodologias e aplicações. São Paulo: Cultura Acadêmica.

Belém, 2018. Cartório de Registro de Imóveis do $2^{\circ}$ Ofício da Comarca de Belém/Pará. Certidão de cadeia dominial da matrícula 8330JI. Registrado em set. 2018.

Brasil, 2001. Medida Provisória n. 2220, de 4 de setembro. Portal da Legislação, Brasília, set. 2001. Disponível em: http://www.planalto.gov.br/ccivil_03/mpv/2220.ht m. Acesso em 22 fev. 2020.

Cabral, L., Cândido, G., 2019. Urbanização, vulnerabilidade, resiliência: relações conceituais e compreensões de causa e efeito. Revista Brasileira de Gestão Urbana, 11 https://doi.org/10.1590/2175-3369.011.002.ao08.

Campos, T. L. de O. B., Mota, M. A. S., Santos, S. R. Q. dos., 2015. Eventos extremos de precipitação em Belém-PA: Uma revisão de notícias históricas de jornais. Rev. Ambient. Água, 10, 182-194. https://doi.org/10.4136/ambi-agua.1433.

Cardoso, M. S. da S, Müller, S. C., Duarte, A. A. A. M., Lima, J. J. F., 2014. Ações de regularização fundiária e de mensuração das desconformidades urbanas: o caso das terras da União sob a tutela da Universidade Federal do Pará na cidade de Belém (PA). Revista Brasileira de Gestão Urbana, 6, 307-322. https://doi.org/10.7213/urbe.06.003.AC03.

Cartier, R., Barcellos, C., Hübner, C., Porto, M. F., 2009. Vulnerabilidade social e risco ambiental: Uma abordagem metodológica para avaliação de injustiça ambiental. Cad. Saúde Pública, 25, 26952704. http://dx.doi.org/10.1590/S0102311X2009001200016. I

Costa, M. A., Marguti, B. O. (Edit.), 2015. Atlas da vulnerabilidade social nas regiões metropolitanas brasileiras. Brasília: IPEA.

Cruz, A. I. G. da, Ambrozio, A. M. H., Puga, F. P., Sousa F. L., Nascimento, M. M., 2012. A economia brasileira: conquistas dos últimos 10 anos e perspectivas para o Futuro. Disponível em: 
https://web.bndes.gov.br/bib/jspui/bitstream/1408/ 961/1/A\%20economia\%20brasileiraconquistas\%20dos\%20ultimos\%20dez $\% 20$ anos $\%$ 20_P-final_BD.pdf. Acesso em: 19 fev. 2021.

Cutter, S. L., 1996. Vulnerability to environmental hazard. Progress in Human Geography. 20, 529539. https://doi.org/10.1177/030913259602000407.

Diaz-Sarachaga, J. M., Jato-Espino, D., 2020. Analysis of vulnerability assessment frameworks and methodologies in urban areas. Natural Hazards, 100, 437-457. https://doi.org/10.1007/s11069-019-03805-y.

Fenzl, N., Machado, J. A. C., 2009. Sustentabilidade dos Sistemas Complexos. Belém: NUMA/UFPA.

IBGE. Instituto Brasileiro de Geografia e Estatística, 2011. Censo Demográfico 2010 - Características da população e dos domicílios: resultados do universo. Disponível em: https://sidra.ibge.gov.br/pesquisa/censodemografico/demografico-2010/universocaracteristicas-da-populacao-e-dos-domicilios. Acesso em: 09 ago. 2019.

IBGE. Instituto Brasileiro de Geografia e Estatística, 2012. Censo Demográfico 2010 - Características urbanísticas do entorno dos domicílios. Disponível em: https://biblioteca.ibge.gov.br/visualizacao/periodi cos/96/cd_2010_entorno_domicilios.pdf. Acesso em: 10 fev. 2021.

Malta, F. S., Costa, E. M., Magrini, A. (2017). Índice de vulnerabilidade socioambiental: uma proposta metodológica utilizando o caso do Rio de Janeiro, Brasil. Ciência \& Saúde Coletiva, 22, 3933-3944. https://doi.org/10.1590/1413812320172212.25032017.

Marandola Jr, E., Hogan, D. J., 2006. As Dimensões da Vulnerabilidade. São Paulo em Perspectiva, 20, 33-43. Disponível em: http://produtos.seade.gov.br/produtos/spp/v20n01/ v20n01_03.pdf. Acesso em: 10 jun 2018.

MME. Ministério de Minas e Energia, 2014. Cartas de Suscetibilidade a Movimentos Gravitacionais de Massa e Inundações - Pará - Belém. Brasília. Escala 1:80.000.

Pereira, Mônani Menine. 2020. A concessão de uso especial para fins de moradia e a máxima da proporcionalidade. Rev. Fac. Dir. Uberlândia [online] 48, 424-437. http://dx.doi.org/10.14393/RFADIR-v48n2a202046876.

Pinto, I. F. de A., 2017. Educação e Desigualdade de Renda no Brasil. Dissertação (Mestrado). Rio de Janeiro, Escola Brasileira de Economia e
Finanças. Disponível em: http://bibliotecadigital.fgv.br/dspace/bitstream/ha ndle/10438/19731/Educa\%C3\%A7\%C3\%A3o\%2 0e\%20Desigualdade $\% 20 \mathrm{de} \% 20$ Renda $\% 20$ no $\% 20$ Brasil\%20-

\%20Isabela\%20Freire\%20de\%20A.\%20Pinto.pdf ?sequence=1\&isAllowed=y. Acesso em: $20 \mathrm{fev}$. 2021.

PNUD. Programa das Nações Unidas para o Desenvolvimento, IPEA. Instituto de Pesquisa Econômica Aplicada, FJP. Fundação João Pinheiro, 2013. Atlas do Desenvolvimento Humano dos Município. Disponível em: https://www.br.undp.org/content/dam/brazil/docs/ IDH/Atlas\%20dos\%20Municipios/undp-br-idhmbrasileiro-atlas-2013-min.pdf. Acesso em: 02 jan. 2021.

Pontes, M. L. C., Lima, A. M. M. de, Silva Júnior, J. de. A., Sadeck, C. C. de A., 2017. Dinâmica das áreas de várzea do município de Belém/PA e a influência da precipitação pluviométrica na formação de pontos alagamentos. Caderno de Geografia, 27(49), 285-303. https://doi.org/10.5752/p.2318-2962.2017 27n49p285.

Santos, V. J. C., 2010. Modelo de processo participativo de enquadramento aplicado a bacias hidrográficas urbanas: bacia do Tucunduba - PA. Dissertação (Mestrado), Belém, Universidade Federal do Pará.

Silva, A. de A., Rocha, G. de M., 2019. Cidade e água: a produção do espaço na Bacia do Igarapé do Tucunduba em Belém-PA. Revista Brasileira de Desenvolvimento Regional, 7, 91-114. http://dx.doi.org/10.7867/23175443.2019v7n1p91-114.

Spinazzola, P. C. S., 2008. Impactos da regularização fundiária no espaço urbano. Dissertação (Mestrado), Universidade de São Paulo, São Paulo. https://doi.org/10.11606/D.16.2008.tde15012010-102847.

UFPA. Universidade Federal do Pará, 2010. Relatório Técnico Conclusivo do Convênio 002/2008 - SEDURB/UFPA. Belém/Pará.

UFPA. Universidade Federal do Pará, 2011. Projeto Regularização Fundiária Urbana: Uma Questão de Cidadania. Belém/Pará.

Vasconcelos, A. C. F. de, Cândido, G. A., Freire, E. M. X., 2019. Vulnerabilidade Socioambiental: Proposição De Temas E Indicadores Para Cidades Brasileiras. Gaia Scientia, 13, 1-18. Disponível em:

https://periodicos.ufpb.br/ojs/index.php/gaia/articl e/view/43357. Acesso em: 20 jan. 2021. 